\title{
CCN3 Facilitates Runx2 and Osterix Expression by Inhibiting miR-608 through PI3K/Akt Signaling in Osteoblasts
}

\author{
Po-Chun Chen ${ }^{1}$, Ju-Fang Liu ${ }^{1}$, Yi-Chin Fong ${ }^{2,3}$, Yuan-Lin Huang ${ }^{4}$, Chia-Chia Chao ${ }^{5}$ and \\ Chih-Hsin Tang 4,6,7,8,*(D) \\ 1 Central Laboratory, Shin-Kong Wu Ho-Su Memorial Hospital, Taipei 111, Taiwan \\ 2 Department of Sports Medicine, College of Health Care, China Medical University, Taichung 404, Taiwan \\ 3 Department of Orthopaedic Surgery, China Medical University Beigang Hospital, Beigang 651, Taiwan \\ 4 Department of Biotechnology, College of Health Science, Asia University, Taichung 413, Taiwan \\ 5 Department of Respiratory Therapy, Fu-Jen Catholic University, New Taipei City 242, Taiwan \\ 6 Department of Pharmacology, School of Medicine, China Medical University, Taichung 404, Taiwan \\ 7 Graduate Institute of Biomedical Science, China Medical University, Taichung 404, Taiwan \\ 8 Chinese Medicine Research Center, China Medical University, Taichung 404, Taiwan \\ * Correspondence: chtang@mail.cmu.edu.tw; Tel.: +886-4-2205-2121-7726; Fax: +886-4-2233-3641
}

Received: 23 May 2019; Accepted: 3 July 2019; Published: 5 July 2019

\begin{abstract}
CCN3, otherwise known as the nephroblastoma overexpressed (NOV) protein, is a cysteine-rich protein that belongs to the CCN family and regulates several cellular functions. Osteoblasts are major bone-forming cells that undergo proliferation, mineralization, renewal, and repair during the bone formation process. We have previously reported that CCN3 increases bone morphogenetic protein 4 (BMP-4) production and bone mineralization in osteoblasts, although the role of CCN3 remains unclear with regard to osteogenic transcription factors (runt-related transcription factor 2 (Runx2) and osterix). Here, we used alizarin red-S and alkaline phosphatase staining to show that CCN3 enhances osteoblast differentiation. Stimulation of osteoblasts with CCN3 increases expression of osteogenic factors such as BMPs, Runx2, and osterix. Moreover, we found that the inhibition of miR-608 expression is involved in the effects of CCN3 and that incubation of osteoblasts with CCN3 promotes focal adhesion kinase (FAK) and Akt phosphorylation. Our results indicate that CCN3 promotes the expression of Runx2 and osterix in osteoblasts by inhibiting miR-608 expression via the FAK and Akt signaling pathways.
\end{abstract}

Keywords: CCN3; osteoblasts; Runx2; osterix; miR-608

\section{Introduction}

Osteoblasts are major bone-forming cells that undergo proliferation, mineralization, renewal, and repair during the bone formation process [1,2]. Accumulating evidence indicates that agents capable of enhancing osteoblastic proliferation or increasing the differentiation of osteoblasts promote bone formation $[3,4]$, thus justifying the approval of the bone formation compound teriparatide 1-34 for osteoporosis therapy [5].

Several osteogenic factors regulate the development and differentiation of osteoblasts, such as bone morphogenetic proteins (BMPs), Runx2, and osterix [6]. BMPs belong to the transforming growth factor- $\beta$ superfamily and play a key role in osteoblastic formation [7], while Runx2 and osterix are important osteogenic transcription factors that control bone mineralization and progression in mesenchymal stem cells and osteoblasts [8,9]. Enhancing Runx2 and osterix transcriptional activities apparently promotes osteoblastic differentiation and facilitates osteogenesis [5,9]. MicroRNAs 
(miRNAs) are small, endogenous non-coding RNAs (18-25 nucleotides in length) that have vital roles as modulators of several physiological and pathological processes $[10,11]$. miRNAs control gene expression at the post-transcriptional level by binding to the three prime untranslated region (3'-UTR) of mRNAs via complementary base pairing, leading to mRNA degradation or translation inhibition [12]. Several miRNAs have been found to modulate osteogenic functions of osteoblasts, including their development, proliferation, survival, and mineralization [12,13]. For instance, miR-6797-5p controls osteoblast differentiation by targeting Runx2 expression [14], while miR-96 regulates bone metabolism by modulating osterix expression [15]. These reports suggest that regulating miRNA expression is a critical tool for controlling osteoblastic function.

$\mathrm{CCN} 3$, otherwise known as the nephroblastoma overexpressed (NOV) protein, is a cysteine-rich protein that belongs to the $\mathrm{CCN}$ family and regulates several cellular functions such as cell proliferation, adhesion, and migration through its interactions with the extracellular matrix (ECM) [16]. CCN3 interacts with many integrin receptors, including integrins $\alpha v \beta 3, \alpha v \beta 5, \alpha 2 \beta 1$ and $\alpha 5 \beta 1$ [16]. The focal adhesion kinase (FAK), MAPK, PI3K, and Akt intracellular signaling pathways are commonly induced by CCN3 [17-19]. There is a lot of evidence that indicates that CCN3 regulates osteogenic factor expression and bone cell differentiation [20,21]. We have previously reported that $\mathrm{CCN} 3$ also increases BMP-4 production and bone mineralization in osteoblasts [17]. However, up until now, the role of $\mathrm{CCN} 3$ in regard to osteogenic transcription factors (Runx2 and osterix) has remained unclear. Here, we report that $\mathrm{CCN} 3$ enhances osteoblast differentiation and also promotes the expression of Runx2 and osterix in osteoblasts by inhibiting miR-608 expression via the FAK and Akt signaling pathways.

\section{Results}

\subsection{CCN3 Promotes Osteoblast Differentiation}

In this study, we examined the role of CCN3 in osteoblast differentiation. After culturing osteoblasts in an osteoblastic differentiation medium (containing vitamin C $50 \mu \mathrm{g} / \mathrm{mL}$ and $\beta$-glycerophosphate $10 \mathrm{mM}$ ) for two weeks, alizarin red-S staining demonstrated that CCN3 promoted bone nodule synthesis (Figure 1A). We also found that CCN3 enhanced ALP expression (a marker for osteoblast differentiation) in a concentration-dependent manner, as according to ALP staining (BMP-2-enhanced ALP staining was used as a positive control) (Figure 1B). These results indicate that CCN3 enhances osteoblast differentiation.

A

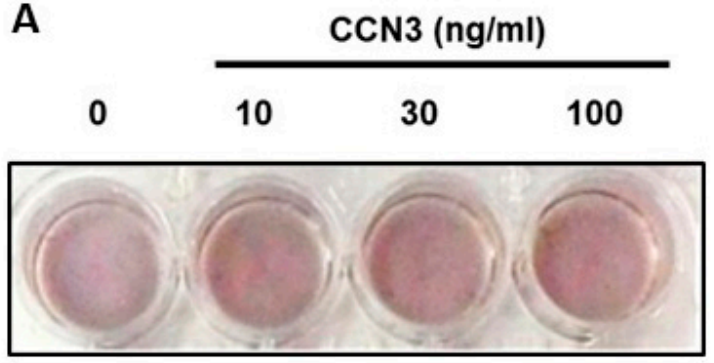

B

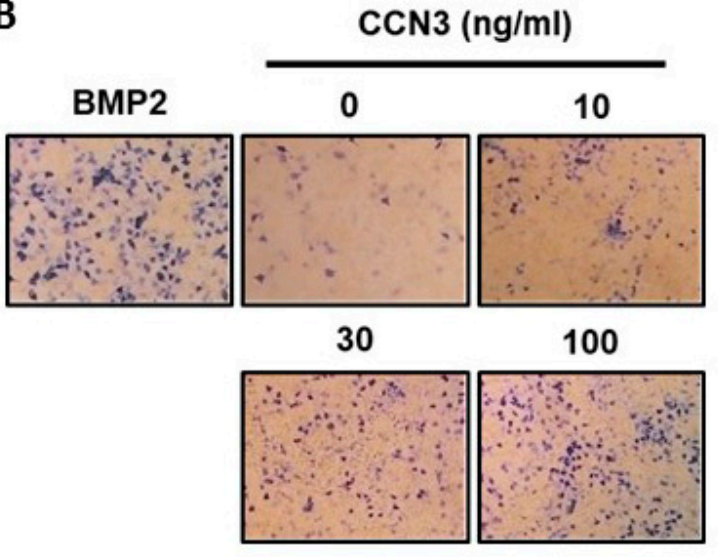

Figure 1. CCN3 enhances osteoblast differentiation. Osteoblasts were plated in 24-well plates and cultured in a medium containing vitamin $\mathrm{C}(50 \mu \mathrm{g} / \mathrm{mL})$ and $\beta$-glycerophosphate $(10 \mathrm{mM})$ for 2 weeks (A) or 2 days (B). The cells were also treated with CCN3. At the end of the experiment, the cultures were fixed and assessed by alizarin red-S (A) and alkaline phosphatase (ALP) staining (B). 


\subsection{CCN3 Enhances Runx2 and Osterix Expression in Osteoblasts}

Treatment of osteoblasts with CCN3 increased mRNA and protein expression of BMP-2, BMP-4, and BMP-7, in a concentration-dependent manner (Figure 2A,C). CCN3 also augmented Runx2 and osterix expression in osteoblasts (Figure $2 \mathrm{~B}, \mathrm{C}$ ). These results suggest that $\mathrm{CCN} 3$ promotes the expression of osteogenic factors in osteoblasts.

A

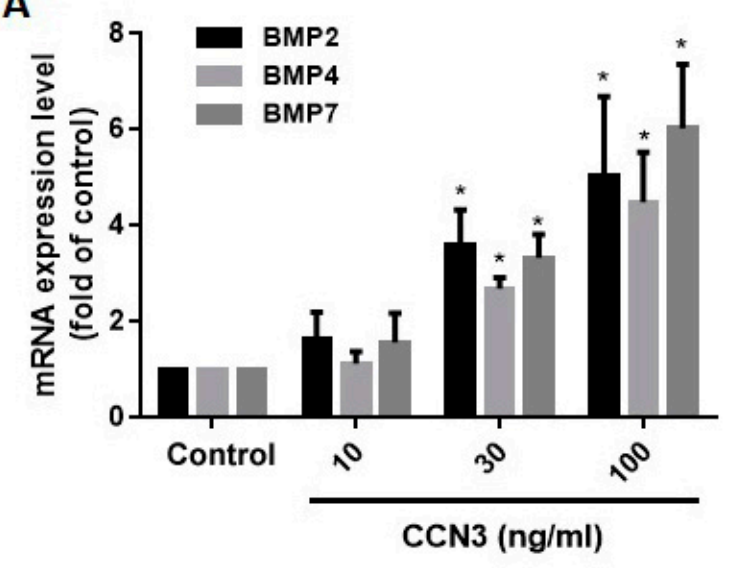

C

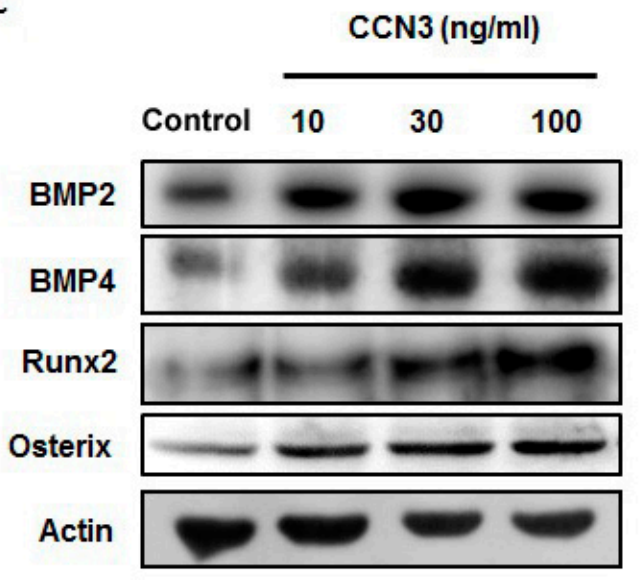

B

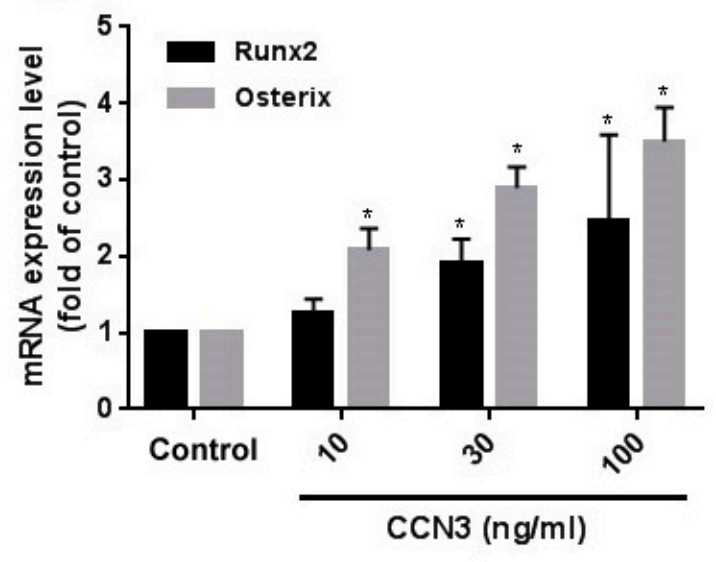

Figure 2. CCN3 enhances osteogenic factor expression in osteoblasts. (A,B) Osteoblasts were treated with CCN3 (10-100 ng/mL) for $24 \mathrm{~h}$; mRNA and protein expression were examined by qPCR (A,B) and Western blot assay $(\mathbf{C})$, respectively. Results are expressed as the mean \pm S.E. ${ }^{*} p<0.05$ as compared with the control group.

\subsection{CCN3 Increases Runx2 and Osterix Expression via the Suppression of miR-608}

The online miRWalk, miRanda, and TargetScan databases revealed that the $3^{\prime}$-UTRs of Runx2 and osterix mRNAs harbor potential binding sites for only miR-608 (Figure 3A). We found that stimulation of CCN3 with osteoblasts concentration-dependently inhibited miR-608 expression (Figure 3B). To examine the role of miR-608 in Runx 2 and osterix expression, the miR-608 mimic was used. Transfection with miR-608 mimic antagonized CCN3-increased Runx2 and osterix expression (Figure 3C,D). To examine whether miR-608 regulates the $3^{\prime}$-UTRs of Runx 2 and osterix, we constructed luciferase reporter vectors harboring either the $3^{\prime}$-UTR of Runx 2 mRNA or the $3^{\prime}$-UTR of osterix mRNA (Figure 4A,B) and transfected them into osteoblasts. CCN3 increased luciferase activity in the Runx2 and osterix plasmids (Figure 4C,D). Transfection with miR-608 mimic reduced CCN3-promoted Runx2 and osterix luciferase activity (Figure 4C,D), suggesting that CCN3 induces Runx2 and osterix activation via the inhibition of miR-608 expression. 
A

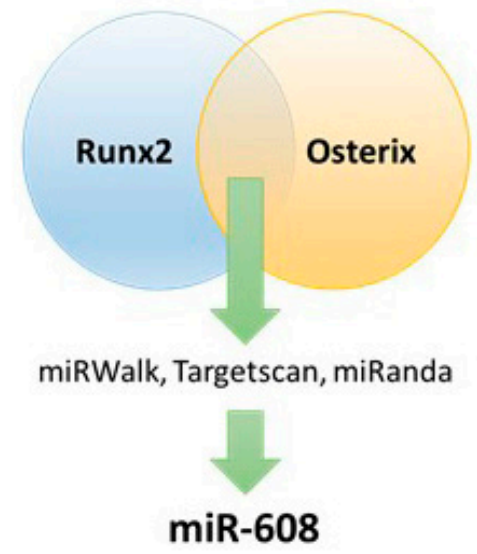

C

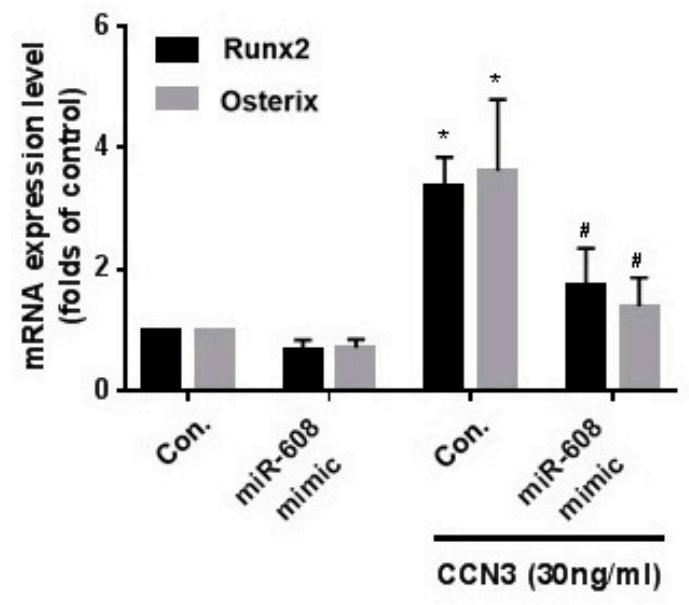

B

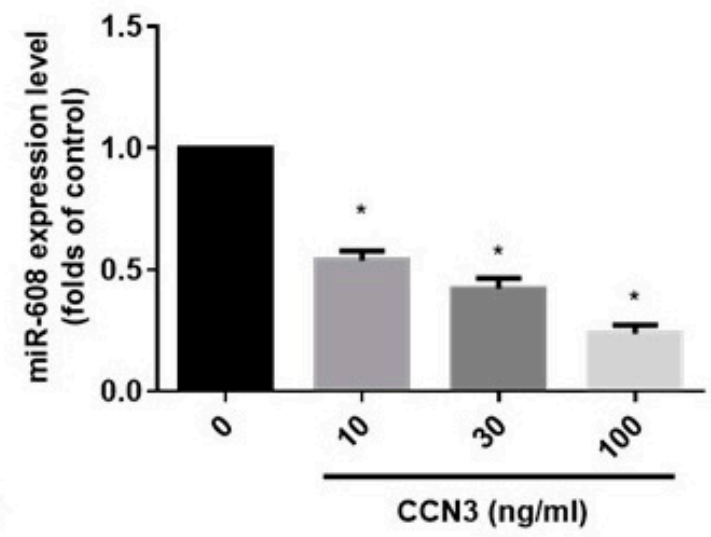

CCN3 $(30 \mathrm{ng} / \mathrm{ml})$

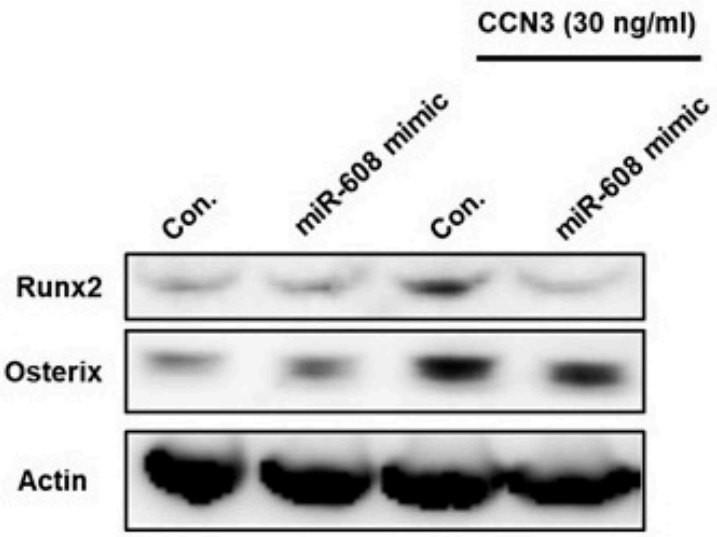

Figure 3. CCN3-induced suppression of miR-608 enhances Runx2 and osterix expression. (A) Open-source software (miRWalk, miRanda, and Targetscan) was utilized to identify microRNAs (miRNAs) that could possibly interfere with Runx2 and osterix transcription. (B) Osteoblasts were incubated with CCN3 for $24 \mathrm{~h}$ and miR-608 expression levels were examined by qPCR assay. Osteoblasts were transfected with miR-608 mimic and subsequently stimulated with CCN3. mRNA and protein expression of Runx2 and osterix were examined by qPCR (C) and Western blot assay (D), respectively. Results are expressed as the mean \pm S.E. ${ }^{*} p<0.05$ as compared with the control group; $\# p<0.05$ as compared with the CCN3-treated group. 
A

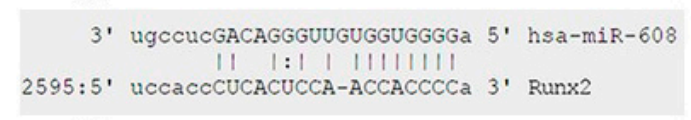

C

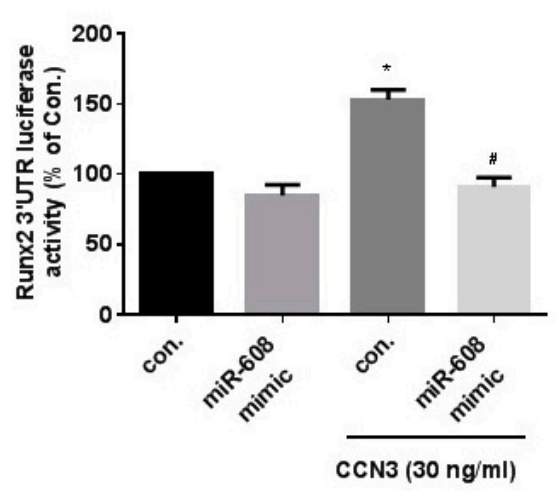

B

3. ugecUCGACAGGGU--UGUGGUGGGGa 5 ' hsa-miR-608 $1010: 5^{\prime}$ agcagGUUCCUCCACUGCCCCACCCCu 3 , Osterix

D

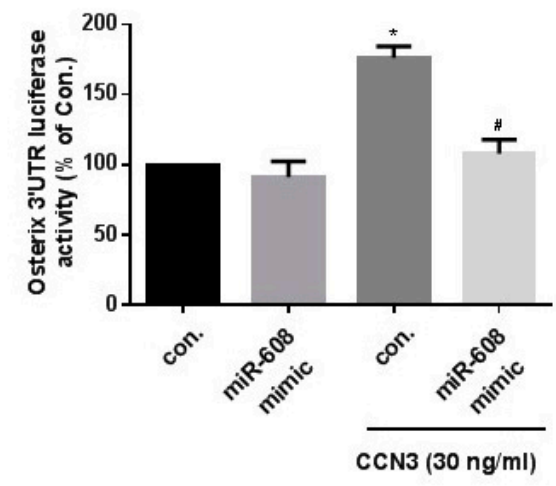

Figure 4. The binding of miR-608 to Runx2 and osterix three prime untranslated region ( $3^{\prime}-\mathrm{UTRs}$ ) mitigated CCN3-induced increases in Runx2 and osterix expression. (A,B) Diagram of the miR-608 binding sites in the Runx2 and osterix $3^{\prime}$-UTRs. (C,D) Osteoblasts were transfected with the Runx2 or osterix $3^{\prime}$-UTR plasmids, with or without miR-608 mimic, then stimulated with CCN3. Luciferase promoter activity was expressed as relative luciferase activity. Results are expressed as the mean \pm S.E. ${ }^{*} p<0.05$ as compared with the control group; $\# p<0.05$ as compared with the CCN3-treated group.

2.4. CCN3 Stimulates Runx2 and Osterix Expression by Inhibiting miR-608 through the FAK and Akt Signaling Pathways

Stimulation of osteoblasts with CCN3 led to a time-dependent increase in phosphorylation of FAK and Akt, as shown by the Western blot assay (Figure 5A). To validate the role of FAK and Akt in CCN3-enhanced Runx2 and osterix expression, osteoblasts were pretreated with FAK and Akt inhibitors or transfected with FAK and Akt mutants. A luciferase activity assay confirmed significant inhibition of CCN3-enhanced Runx2 and osterix luciferase activities, as shown in Figure 5B,C. In addition, FAK and Akt inhibitors or mutants reversed CCN3-inhibited miR-608 expression (Figure 5D). These data suggest that miR-608 directly suppresses Runx2 and osterix gene transcription via binding to the $3^{\prime}$-UTR region of the human Runx 2 and osterix gene promoter, and that miR-608 expression is negatively regulated by FAK and Akt phosphorylation induced by upstream CCN3 signaling. 


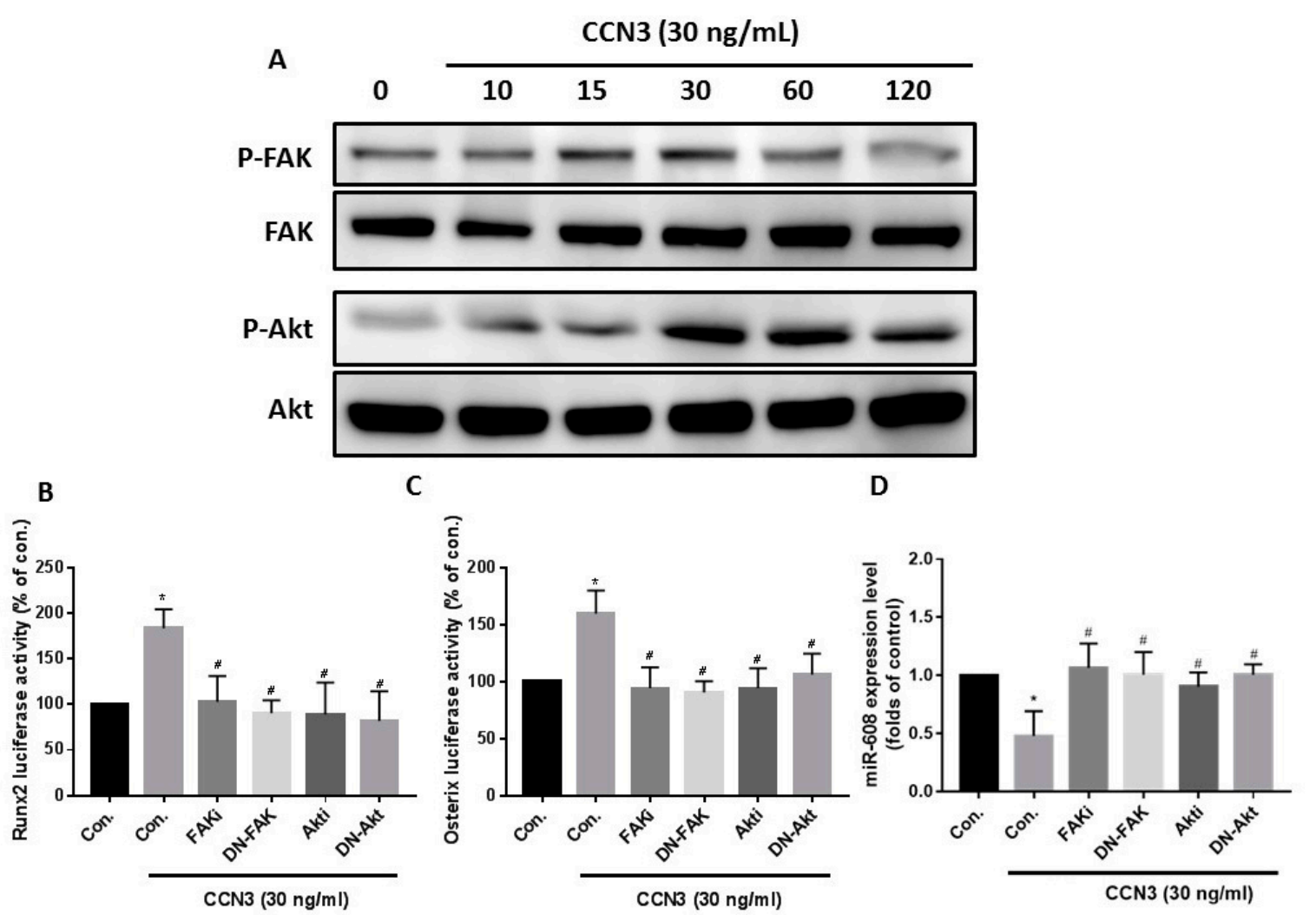

Figure 5. CCN3 suppressed miR-608 expression through the FAK and Akt signaling pathways. (A) Osteoblasts were treated with CCN3 $(30 \mathrm{ng} / \mathrm{mL})$ for the indicated time intervals; FAK and Akt phosphorylation were examined by Western blot assay. Osteoblasts were pretreated with FAK and Akt inhibitors or transfected with FAK and Akt mutants and subsequently stimulated with CCN3. Runx2 and osterix luciferase activity and miR-608 expression were examined by luciferase assay $(\mathbf{B}, \mathbf{C})$ and qPCR (D), respectively. Results are expressed as the mean \pm S.E. ${ }^{*} p<0.05$ as compared with the control group; $\# p<0.05$ as compared with the CCN3-treated group.

\section{Discussion}

The proliferation and differentiation of osteoblasts is regulated by different endogenous factors [22]. CCN3 promotes BMP-4-dependent bone mineralization in osteoblasts [17], although the effects of CCN3 upon two important osteogenic transcription factors, Runx 2 and osterix, are largely unknown. In the current study, we found that CCN3 promotes BMP expression and the differentiation of osteoblasts and that CCN3 stimulation increases Runx 2 and osterix expression by inhibiting miR-608 expression via the FAK and Akt signaling pathways. We also found that CCN3 increases levels of BMP, Runx2, and osterix expression in osteoblasts. Conversely, BMP has been implicated in the enhancement of Runx2 and osterix activity [23]. Whether CCN3 promotes Runx2 and osterix activation via a BMP-dependent effect needs further examination.

Controversy surrounds the contention that CCN3 modulates bone cell function. Rydziel et al. indicated that CCN3 inhibits osteoblastogenesis and causes osteopenia in vivo [21] and another research group also found that $\mathrm{CCN} 3$ inhibits osteoblast differentiation through the inhibition of BMP-2 expression in osteoblast precursor cells [20], while a higher dosage of CCN3 (600 ng/mL) inhibits the differentiation of primary bone marrow cells [24]. However, we have previously reported that CCN3 enhances BMP-4-dependent bone mineralization [17]. The results of this current study support our previous finding that $\mathrm{CCN} 3$ enhances osteoblast differentiation. In addition, we found that CCN3 stimulation upregulated levels of osteogenic factors, including BMP-2, BMP-4, BMP-7, Runx2, and osterix. The opposite effect may therefore depend on the working concentration of $\mathrm{CCN} 3$, as we found 
that a lower dosage of CCN3 $(30 \mathrm{ng} / \mathrm{mL})$ increases osteoblast differentiation, whereas a higher CCN3 dosage $(600 \mathrm{ng} / \mathrm{mL})$ reportedly inhibits this phenomenon. Otherwise, most inhibitory effects have been found through the overexpression of CCN3. However, this effect may depend on the route of treatment, as in this study, we applied exogenous recombinant CCN3 to osteoblasts. Several different cells have been used in bone function assays, including primary bone marrow cells, stromal cells, and osteoblastic cells. Thus, the opposite effect may depend on the concentration, timing of the stimulation, route of treatment, and type of cell.

miRNAs are small, non-coding RNA fragments that suppress the translation or induce the degradation of target mRNAs [25]. A multitude of miRNAs are known to be involved in bone-related disorders [26-28]. We utilized open-source software (miRWalk, miRanda, and TargetScan) to evaluate candidate miRNAs that may interfere with the transcription of Runx2 and osterix. Among the selected miRNAs, only miR-608 regulated both Runx2 and osterix transcriptional activity. We have shown that transfecting osteoblasts with miR-608 mimic mitigates CCN3-stimulated Runx2 and osterix expression. These findings underscore the importance of miR-608 in CCN3-stimulated Runx2 and osterix expression. BMP family proteins play a critical role in bone formation and differentiation [29]. However, we have not found any reports in the literature regarding miR-608-induced regulation of BMPs. Whether BMPs also modulate miR-608-dependent bone formation needs further examination. miR-608 activity has been mentioned in several cancers; for example, miR-608 regulates apoptosis in lung adenocarcinoma [30] and the miR-608 $\mathrm{rs} 4919510 \mathrm{C}>\mathrm{G}$ polymorphism is associated with a significantly lower risk of breast cancer [31]. However, the effects of miR-608 in bone cells are not yet quantified. Whether miR-608 also controls other bone cell functions needs further investigation.

Activation of the FAK pathway regulates osteoblast adhesion and differentiation [32,33]. Akt activation is also implicated in osteoblastic functions [34,35]. In this investigation, CCN3 augmented the phosphorylation of FAK and Akt. In addition, FAK, Akt inhibitors, and their associated mutants all abolished CCN3-induced elevations in Runx2 and osterix expression, indicating that FAK and Akt signaling mediates the effects of CCN3. These inhibitors and their mutants also reversed CCN3-inhibited expression of miR-608, suggesting that the FAK/Akt pathway acts as an upstream molecule of miR-608. These findings provide evidence showing that CCN3 enhances the expression of transcription factors Runx 2 and osterix by inhibiting miR-608 expression via the FAK and Akt signaling cascades. We previously reported that CCN3 regulates BMP-4 production through the MAPK pathway [17]. Treatment of osteoblasts with ERK, p38, and JNK inhibitors reversed CCN3-inhibted miR-608 expression (data not shown), suggesting that the MAPK pathway is also involved in CCN3-induced miR-608 suppression.

\section{Materials and Methods}

\subsection{Materials}

We obtained recombinant human CCN3 and BMP-2 from PeproTech (Rocky Hill, NJ, USA) and purchased BMP-2, BMP-4, Runx2, and osterix antibody from Abnova (Taipei, Taiwan). Antibodies against p-FAK, FAK, p-Akt, Akt, and $\beta$-actin were purchased from Santa Cruz (Santa Cruz, CA, USA) and cell culture supplements from Invitrogen (Carlsbad, CA, USA). The Dual-Luciferase ${ }^{\circledR}$ Reporter Assay System was purchased from Promega (Madison, WI, USA). Quantitative polymerase chain reaction (qPCR) primers and probes, as well as the Taqman ${ }^{\circledR}$ one-step PCR Master Mix, were supplied by Applied Biosystems (Foster City, CA, USA). All other chemicals not mentioned above were supplied by Sigma-Aldrich (St Louis, MO, USA). The FAK dominant-negative (DN) mutant was a gift from Dr. J. A. Girault (Institut du Fer á Moulin, Paris, France). The Akt DN mutant was gifted by Dr. W. M. Fu (National Taiwan University, Taipei, Taiwan). 


\subsection{Cell Culture}

The osteoblastic cell line MC3T3-E1 was purchased from American Type Culture Collection (Manassas, VA, USA). Cells were cultured in culture media containing alpha-minimal essential medium $(\alpha$-MEM) supplemented with streptomycin $(100 \mu \mathrm{g} / \mathrm{mL})$, penicillin $(100 \mathrm{U} / \mathrm{mL})$, HEPES $(20 \mathrm{mM})$, glutamine $(2 \mathrm{mM})$, and $10 \%$ fetal bovine serum (FBS), then maintained at $37^{\circ} \mathrm{C}$ in an atmosphere of humidified air with $5 \% \mathrm{CO}_{2}$.

\subsection{Measurement of Osteoblast Differentiation}

Cells were cultured in a medium containing vitamin C $(50 \mu \mathrm{g} / \mathrm{mL}), \beta$-glycerophosphate $(10 \mathrm{mM})$, and CCN3 $(10-30 \mathrm{ng} / \mathrm{mL})$ for 2 weeks. Cells were fixed in ice-cold $75 \%(v / v)$ ethanol for $30 \mathrm{~min}$ and the calcium deposition was determined using $40 \mathrm{mM}$ alizarin red-S staining (pH 4.2) [36].

For alkaline phosphatase (ALP) staining, the cells were fixed with acetone for $30 \mathrm{~s}$ then stained

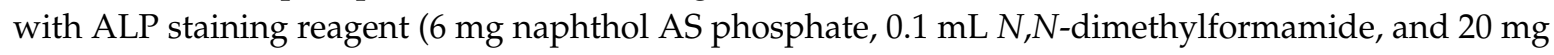
Fast Blue BB salt in $20 \mathrm{~mL}$ of $0.5 \mathrm{M}$ Tris buffer; $\mathrm{pH} 10.2$ ). Images were photographed using a microscope (Nikon, Kanagawa, Japan) [37].

\subsection{Western Blot Analysis}

Cell lysates were prepared by RIPA buffer containing a protease inhibitor cocktail (Sigma-Aldrich; St Louis, MO, USA); extracted proteins were analyzed by sodium dodecyl sulfate polyacrylamide gel electrophoresis and transferred to Immobilon ${ }^{\circledR}$ polyvinylidene difluoride membranes. The blots were treated with $4 \%$ bovine serum albumin (BSA) for $1 \mathrm{~h}$ and then with primary antibodies (1:3000) for $1 \mathrm{~h}$. The membranes were treated with peroxidase-conjugated secondary antibody (1:3000) for $1 \mathrm{~h}$. Finally, the bands were visualized using ImageQuant ${ }^{\mathrm{TM}}$ LAS 4000 (GE Healthcare, Little Chalfont, UK) [38,39].

\subsection{Quantitative Real-Time PCR}

Total cDNA (100 ng) was mixed with Taqman ${ }^{\circledR}$ primers and probes as well as PCR Master Mix. The StepOnePlus ${ }^{\mathrm{TM}}$ system was used in the quantitative RT-PCR assays. BMP-2 (F) GGGACCCGCTGTCTTCTAGT, BMP-2 (R) TCAACTCAAATTCGCTGAGGAC; BMP-4 (F) TTCCTGGTAACCGAATGCTGA, BMP-4 (R) CCTGAATCTCGGCGACTTTTT; BMP-7 (F) ACGGACAGGGCTTCTCCTAC， BMP-7 (R) ATGGTGGTATCGAGGGTGGAA; Runx2 (F) CCAACCGAGTCATTTAAGGCT, Runx2 (R) GCTCACGTCGCTCATCTTG; osterix (F) ATGGCGTCCTCTCTGCTTG, osterix (R) TGAAAGGTCAGCGTATGGCTT. For the detection of miRNAs, reverse transcription was performed using Mir- $\mathrm{X}^{\mathrm{TM}}$ miRNA First-Strand Synthesis and the SYBR ${ }^{\circledR}$ RT-PCR kit. qPCR analysis was carried out according to an established protocol $[40,41]$.

\subsection{Plasmid Construct and Reporter Assay}

We obtained Runx2 and osterix 3'-UTR DNA fragments from Invitrogen (Carlsbad, CA, USA) and subcloned them into the pmirGLO-control luciferase reporter vector (Promega, Madison, WI, USA). Luciferase activity was assayed using the method as described in our previous research $[42,43]$.

\subsection{Statistics}

All values are presented as the mean \pm the standard error (S.E.). All differences between the experimental groups and controls were assessed for significance using the Student's $t$-test. Between-group differences were considered to be significant if the $p$ value was $<0.05$.

\section{Conclusions}

In summary, our study shows that the binding of CCN3 in osteoblasts triggers the phosphorylation of FAK and Akt, contributing to the decline in miR-608 synthesis. The decrease in miR-608 expression 
enhances the synthesis of osteogenic transcription factors Runx2 and osterix (Figure 6). These results may improve understanding of the role played by CCN3 in osteoblast differentiation.
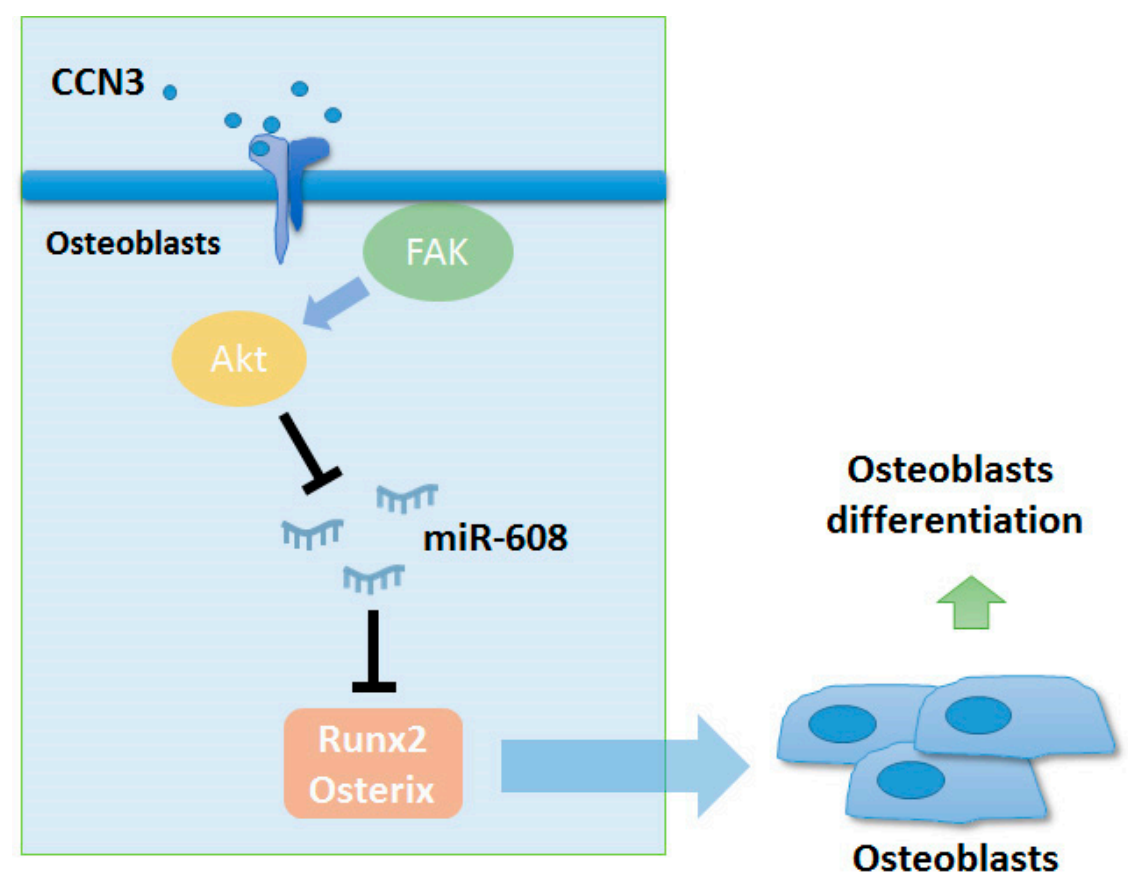

Figure 6. Schematic diagram summarizes the mechanism whereby CCN3 promotes Runx2 and osterix expression in osteoblasts. CCN3 promotes the expression of osteogenic transcriptional factors Runx2 and osterix in osteoblasts by downregulating miR-608 through the focal adhesion kinase (FAK) and Akt signaling pathway.

Author Contributions: Formal analysis, P.-C.C., J.-F.L. and C.-C.C.; funding acquisition, Y.-C.F. and C.-H.T.; methodology, P.-C.C., J.-F.L., Y.-L.H. and C.-C.C.; writing-review and editing, C.-H.T.

Funding: This work was supported by grants from Taiwan's Ministry of Science and Technology (MOST 107-2320-B-341-001-MY2) and China Medical University (CMU 103-ASIA-03).

Acknowledgments: The authors wish to acknowledge the help of the Urological Research Group of Shin Kong Wu Ho-Su Memorial Hospital, under the administration of Thomas I-sheng Hwang, who provided us with clinical advice and commented upon this work. We also thank Jean-Antoine Girault for providing a FAK mutant and Wen-Mei Fu for providing an Akt mutant.

Conflicts of Interest: The authors have no financial or personal relationships that could inappropriately influence this research.

\section{References}

1. Seeman, E.; Martin, T.J. Antiresorptive and anabolic agents in the prevention and reversal of bone fragility. Nat. Rev. Rheumatol. 2019, 15, 225-236. [CrossRef] [PubMed]

2. Kim, B.J.; Koh, J.M. Coupling factors involved in preserving bone balance. Cell. Mol. Life Sci. CMLS 2019, 76, 1243-1253. [CrossRef] [PubMed]

3. Letarouilly, J.G.; Broux, O.; Clabaut, A. New insights into the epigenetics of osteoporosis. Genomics 2018. [CrossRef]

4. Baron, R.; Gori, F. Targeting wnt signaling in the treatment of osteoporosis. Curr. Opin. Pharmacol. 2018, 40, 134-141. [CrossRef] [PubMed]

5. Liu, Y.; Levack, A.E.; Marty, E.; Or, O.; Samuels, B.P.; Redko, M.; Lane, J.M. Anabolic agents: What is beyond osteoporosis? Osteoporos. Int. 2018, 29, 1009-1022. [CrossRef] [PubMed]

6. Li, X.; Zhang, J.; Wang, X. Bone minimodeling, a special modeling pattern and potential as therapeutic target for osteoporosis. Curr. Mol. Med. 2018, 18, 233-240. [CrossRef] 
7. Wu, D.H.; Hatzopoulos, A.K. Bone morphogenetic protein signaling in inflammation. Exp. Biol. Med. 2019, 244, 147-156. [CrossRef] [PubMed]

8. Liu, T.M.; Lee, E.H. Transcriptional regulatory cascades in Runx2-dependent bone development. Tissue Eng. Part B Rev. 2013, 19, 254-263. [CrossRef]

9. Long, F. Building strong bones: Molecular regulation of the osteoblast lineage. Nat. Rev. Mol. Cell Biol. 2011, 13, 27-38. [CrossRef]

10. Mourelatos, Z. Small rnas: The seeds of silence. Nature 2008, 455, 44-45. [CrossRef]

11. Rodriguez, A.; Griffiths-Jones, S.; Ashurst, J.L.; Bradley, A. Identification of mammalian microrna host genes and transcription units. Genome Res. 2004, 14, 1902-1910. [CrossRef] [PubMed]

12. Taipaleenmaki, H. Regulation of bone metabolism by micrornas. Curr. Osteoporos. Rep. 2018, 16, 1-12. [CrossRef] [PubMed]

13. Bellavia, D.; De Luca, A.; Carina, V.; Costa, V.; Raimondi, L.; Salamanna, F.; Alessandro, R.; Fini, M.; Giavaresi, G. Deregulated mirnas in bone health: Epigenetic roles in osteoporosis. Bone 2019, 122, 52-75. [CrossRef] [PubMed]

14. Arumugam, B.; Vishal, M.; Shreya, S.; Malavika, D.; Rajpriya, V.; He, Z.; Partridge, N.C.; Selvamurugan, N. Parathyroid hormone-stimulation of Runx2 during osteoblast differentiation via the regulation of lnc-SUPT3H-1:16 (RUNX2-AS1:32) and miR-6797-5p. Biochimie 2019, 158, 43-52. [CrossRef] [PubMed]

15. Liu, H.; Liu, Q.; Wu, X.P.; He, H.B.; Fu, L. MiR-96 regulates bone metabolism by targeting osterix. Clin. Exp. Pharmacol. Physiol. 2018, 45, 602-613. [CrossRef] [PubMed]

16. Chen, P.C.; Cheng, H.C.; Yang, S.F.; Lin, C.W.; Tang, C.H. The CCN family proteins: Modulators of bone development and novel targets in bone-associated tumors. BioMed Res. Int. 2014, 2014, 437096. [CrossRef] [PubMed]

17. Tan, T.W.; Huang, Y.L.; Chang, J.T.; Lin, J.J.; Fong, Y.C.; Kuo, C.C.; Tsai, C.H.; Chen, Y.J.; Hsu, H.C.; Cho, D.Y.; et al. CCN3 increases BMP-4 expression and bone mineralization in osteoblasts. J. Cell. Physiol. 2012, 227, 2531-2541. [CrossRef]

18. Chen, P.C.; Cheng, H.C.; Wang, J.; Wang, S.W.; Tai, H.C.; Lin, C.W.; Tang, C.H. Prostate cancer-derived CCN3 induces M2 macrophage infiltration and contributes to angiogenesis in prostate cancer microenvironment. Oncotarget 2014, 5, 1595-1608. [CrossRef]

19. Tzeng, H.E.; Chen, J.C.; Tsai, C.H.; Kuo, C.C.; Hsu, H.C.; Hwang, W.L.; Fong, Y.C.; Tang, C.H. CCN3 increases cell motility and MMP-13 expression in human chondrosarcoma through integrin-dependent pathway. J. Cell. Physiol. 2011, 226, 3181-3189. [CrossRef]

20. Minamizato, T.; Sakamoto, K.; Liu, T.; Kokubo, H.; Katsube, K.; Perbal, B.; Nakamura, S.; Yamaguchi, A. CCN3/NOV inhibits BMP-2-induced osteoblast differentiation by interacting with BMP and notch signaling pathways. Biochem. Biophys. Res. Commun. 2007, 354, 567-573. [CrossRef]

21. Rydziel, S.; Stadmeyer, L.; Zanotti, S.; Durant, D.; Smerdel-Ramoya, A.; Canalis, E. Nephroblastoma overexpressed (Nov) inhibits osteoblastogenesis and causes osteopenia. J. Biol. Chem. 2007, 282, 19762-19772. [CrossRef] [PubMed]

22. Almeida, M.; Porter, R.M. Sirtuins and foxos in osteoporosis and osteoarthritis. Bone 2019, 121, $284-292$. [CrossRef] [PubMed]

23. Li, Z.; Wang, W.; Xu, H.; Ning, Y.; Fang, W.; Liao, W.; Zou, J.; Yang, Y.; Shao, N. Effects of altered CXCL12/CXCR4 axis on BMP2/smad/Runx2/osterix axis and osteogenic gene expressions during osteogenic differentiation of MSCs. Am. J. Transl. Res. 2017, 9, 1680-1693. [PubMed]

24. Ouellet, V.; Tiedemann, K.; Mourskaia, A.; Fong, J.E.; Tran-Thanh, D.; Amir, E.; Clemons, M.; Perbal, B.; Komarova, S.V.; Siegel, P.M. CCN3 impairs osteoblast and stimulates osteoclast differentiation to favor breast cancer metastasis to bone. Am. J. Pathol. 2011, 178, 2377-2388. [CrossRef] [PubMed]

25. He, L.; Hannon, G.J. Micrornas: Small rnas with a big role in gene regulation. Nat. Rev. Genet. 2004, 5, 522-531. [CrossRef] [PubMed]

26. Asahara, H. Current status and strategy of microrna research for cartilage development and osteoarthritis pathogenesis. J. Bone Metab. 2016, 23, 121-127. [CrossRef]

27. Yang, W.H.; Tsai, C.H.; Fong, Y.C.; Huang, Y.L.; Wang, S.J.; Chang, Y.S.; Tang, C.H. Leptin induces oncostatin M production in osteoblasts by downregulating miR-93 through the akt signaling pathway. Int. J. Mol. Sci. 2014, 15, 15778-15790. [CrossRef] 
28. Cui, Q.; Xing, J.; Yu, M.; Wang, Y.; Xu, J.; Gu, Y.; Nan, X.; Ma, W.; Liu, H.; Zhao, H. Mmu-miR-185 depletion promotes osteogenic differentiation and suppresses bone loss in osteoporosis through the bgn-mediated BMP/smad pathway. Cell Death Dis. 2019, 10, 172. [CrossRef]

29. Lowery, J.W.; Rosen, V. The bmp pathway and its inhibitors in the skeleton. Physiol. Rev. 2018, 98, 2431-2452. [CrossRef]

30. Othman, N.; Nagoor, N.H. MiR-608 regulates apoptosis in human lung adenocarcinoma via regulation of AKT2. Int. J. Oncol. 2017, 51, 1757-1764. [CrossRef]

31. Hashemi, M.; Sanaei, S.; Rezaei, M.; Bahari, G.; Hashemi, S.M.; Mashhadi, M.A.; Taheri, M.; Ghavami, S. miR-608 rs4919510 C>G polymorphism decreased the risk of breast cancer in an iranian subpopulation. Exp. Oncol. 2016, 38, 57-59. [CrossRef]

32. Ma, X.Y.; Feng, Y.F.; Wang, T.S.; Lei, W.; Li, X.; Zhou, D.P.; Wen, X.X.; Yu, H.L.; Xiang, L.B.; Wang, L. Involvement of FAK-mediated BMP-2/smad pathway in mediating osteoblast adhesion and differentiation on nano-HA/chitosan composite coated titanium implant under diabetic conditions. Biomater. Sci. 2017, 6, 225-238. [CrossRef] [PubMed]

33. Tsai, S.Y.; Huang, Y.L.; Yang, W.H.; Tang, C.H. Hepatocyte growth factor-induced BMP-2 expression is mediated by c-Met receptor, FAK, JNK, Runx2, and p300 pathways in human osteoblasts. Int. Immunopharmacol. 2012, 13, 156-162. [CrossRef] [PubMed]

34. Wu, C.M.; Chen, P.C.; Li, T.M.; Fong, Y.C.; Tang, C.H. Si-wu-tang extract stimulates bone formation through PI3K/Akt/NF-kappaB signaling pathways in osteoblasts. BMC Complement. Altern. Med. 2013, 13, 277. [CrossRef] [PubMed]

35. Tang, C.H.; Yang, R.S.; Huang, T.H.; Lu, D.Y.; Chuang, W.J.; Huang, T.F.; Fu, W.M. Ultrasound stimulates cyclooxygenase-2 expression and increases bone formation through integrin, focal adhesion kinase, phosphatidylinositol 3-kinase, and akt pathway in osteoblasts. Mol. Pharmacol. 2006, 69, 2047-2057. [CrossRef]

36. Chang, A.C.; Chen, P.C.; Lin, Y.F.; Su, C.M.; Liu, J.F.; Lin, T.H.; Chuang, S.M.; Tang, C.H. Osteoblast-secreted WISP-1 promotes adherence of prostate cancer cells to bone via the VCAM-1/integrin alpha4beta1 system. Cancer Lett. 2018, 426, 47-56. [CrossRef]

37. Lin, T.H.; Tang, C.H.; Hung, S.Y.; Liu, S.H.; Lin, Y.M.; Fu, W.M.; Yang, R.S. Upregulation of heme oxygenase-1 inhibits the maturation and mineralization of osteoblasts. J. Cell. Physiol. 2010, 222, 757-768. [CrossRef]

38. Lee, H.P.; Chen, P.C.; Wang, S.W.; Fong, Y.C.; Tsai, C.H.; Tsai, F.J.; Chung, J.G.; Huang, C.Y.; Yang, J.S.; Hsu, Y.M.; et al. Plumbagin suppresses endothelial progenitor cell-related angiogenesis in vitro and in vivo. J. Funct. Foods 2019, 52, 537-544. [CrossRef]

39. Wang, X.; Sheu, J.J.; Lai, M.T.; Chang, C.Y.; Sheng, X.; Wei, L.; Gao, Y.; Wang, X.; Liu, N.; Xie, W.; et al. RSF-1 overexpression determines cancer progression and drug resistance in cervical cancer. BioMedicine 2018, 8, 4 . [CrossRef]

40. Wu, M.H.; Lo, J.F.; Kuo, C.H.; Lin, J.A.; Lin, Y.M.; Chen, L.M.; Tsai, F.J.; Tsai, C.H.; Huang, C.Y.; Tang, C.H. Endothelin-1 promotes MMP-13 production and migration in human chondrosarcoma cells through FAK/PI3K/Akt/mTOR pathways. J. Cell. Physiol. 2012, 227, 3016-3026. [CrossRef]

41. Hou, C.H.; Hsiao, Y.C.; Fong, Y.C.; Tang, C.H. Bone morphogenetic protein-2 enhances the motility of chondrosarcoma cells via activation of matrix metalloproteinase-13. Bone 2009, 44, 233-242. [CrossRef] [PubMed]

42. Lien, M.Y.; Tsai, H.C.; Chang, A.C.; Tsai, M.H.; Hua, C.H.; Wang, S.W.; Tang, C.H. Chemokine CCL4 induces vascular endothelial growth factor $C$ expression and lymphangiogenesis by miR-195-3p in oral squamous cell carcinoma. Front. Immunol. 2018, 9, 412. [CrossRef] [PubMed]

43. Chao, C.C.; Chen, P.C.; Chiou, P.C.; Hsu, C.J.; Liu, P.I.; Yang, Y.C.; Reiter, R.J.; Yang, S.F.; Tang, C.H. Melatonin suppresses lung cancer metastasis by inhibition of epithelial-mesenchymal transition through targeting to twist. Clin. Sci. 2019, 133, 709-722. [CrossRef] [PubMed]

(C) 2019 by the authors. Licensee MDPI, Basel, Switzerland. This article is an open access article distributed under the terms and conditions of the Creative Commons Attribution (CC BY) license (http://creativecommons.org/licenses/by/4.0/). 